\title{
DAPATKAH MODEL BLENDED LEARNING MEMPENGARUHI KEMANDIRIAN BELAJAR MATEMATIKA SISWA?
}

\author{
Budi Yanto ${ }^{1}$, Heri Retnawati ${ }^{2}$ \\ ${ }^{1,2}$ Pendidikan Matematika, Universitas Negeri Yogyakarta \\ E-mail: $\quad$ budiyanto38b@gmail.com ${ }^{1)}$ \\ Heri_retnawati@uny.com ${ }^{2}$
}

Received 2 October 2018; Received in revised form 10 November 2018; Accepted 23 December 2018

\begin{abstract}
This research aims to determine the effect of the blended learning model on self-regulated learning of mathematics student. The design of this study is a quasi-experimental. The study population was all eighth-grade students at SMPN 1 Way Tenong in West Lampung which consisted of 7 classes. The experimental class was chosen randomly because the school has available internet networks and devices that can access the internet and students have the ability to access the internet. The instrument used was the self-regulated learning of mathematics questionnaire. Questionnaire of self-regulated learning is arranged on a Likert scale with categories always, often, sometimes, rarely, and never. The measured aspects of self-regulated learning are self-initiative, setting learning goals and strategies, as well as evaluating or self-reflection. The data analysis technique uses inferential analysis. Pretest and posttest data have been calculated and declared to be normally distributed. To find out the increasing selfregulated learning mathematics used the gain test. The results of the $t$-test between the pre-test and posttest obtained the t-test value of 10.744 and significant $0.000<p(0.05)$. The results of this research indicate that the blended learning model can influence self-regulated learning mathematics. The gain test results show that all students experience an increase in self-regulated learning. Self-initiative and selfevaluation or reflection show the improvement with the criteria of the medium, while aspects of setting goals and learning strategies show improvement with high criteria.
\end{abstract}

Keywords: Blended learning, Self-Regulated Learning

\section{PENDAHULUAN}

Perkembangan

teknologi informasi dan komunikasi abad ke-21 memungkinkan setiap orang dapat berinteraksi dengan orang lain tanpa melalui kontak langsung atau tatap muka. Hal ini juga dapat terjadi dalam pembelajaran, guru dan siswa dapat berinteraksi tanpa tatap muka melainkan menggunakan bantuan teknologi. Inovasi pembelajaran yang memanfaatkan teknologi komputer dan internet akan memberikan suasana berbeda terhadap persepsi siswa terhadap permbelajaran. (Sujoko, 2013: 73). Penggunaan internet dapat menjadi alternatif dalam merancang pembelajaran yang lebih menarik, interaktif dan variatif (Sujoko, 2013: 72). Siswa juga dapat belajar secara mandiri dan mengembangkan pengetahuan seluas-luasnya dengan memanfaatkan jaringan internet (Fatwa dan Djuniadi, 2016: 104).

$$
\text { Kegiatan siswa dalam }
$$

pembelajaran bukan hanya

mendapatkan informasi dari guru saja, melainkan siswa harus membangun sendiri konsep dan prinsip yang dipelajari. Kemandirian belajar dibutuhkan oleh siswa dalam membangun konsep dan prinsip yang dipelajarinya (Purnamasari, 2012: 4). Self-Regulated Learning atau kemandirian belajar adalah sikap untuk tidak bergantung kepada orang lain dalam kegiaan belajar, disertai gigih dalam usaha, bebas menentukan pilihan sendiri, memiliki inisiatif, bertindak secara efektif terhadap lingkungannya,

\section{4 | AKSIOMA}

Jurnal Pendidikan Matematika FKIP Univ. Muhammadiyah Metro 
serta konsekuen dalam mencapai tujuan yang diharapkan (Aziz dan Basry, 2017: 22). Kemandirian belajar digambarkan sebagai proses siklis yang melibatkan beberapa hal yaitu menetapkan tujuan, pemantauan proses dan strategi belajar, dan evaluasi diri (Beishuizen dan Steffens, 2011: 4). Kemandirian belajar adalah proses proaktif yang digunakan siswa memperoleh keterampilan akademik, seperti menetapkan tujuan, memilih dan menerapkan strategi, dan memantau efektivitasnya sendiri (Eliserio, 2012: 1). Siswa dikatakan memiliki kemandirian jika berinisiatif belajar, memiliki kemampuan menentukan nasib sendiri, mendiagnosis kebutuhan belajar, kreatif dan inisiatif dalam memanfaatkan sumber belajar dan memilih strategi belajar serta memonitor, mengatur, dan mengontrol belajar (Lestari dan Yudhanegara, 2015: 94). Dapat diketahui bahwa, kemandirian belajar adalah suatu kondisi seorang individu memiliki inisitatif untuk belajar, menetapkan tujuan belajar dan strategi belajar, dan mengevaluasi atau refleksi diri dalam kegiatan belajarnya.

Matematika masih dianggap sulit, karena identik dengan sederetan angkaangka, simbol-simbol, dan rumus-rumus yang dapat diselesaikan melalui operasi hitung matematika (Amiluddin dan Sugiman, 2016: 101). Hal ini dapat mempengaruhi siswa malas dan cenderung menghindari belajar matematika. Pembelajaran matematika di sekolah masih dianggap siswa kurang menarik dan kurang menyenangkan sehingga siswa tidak termotivasi untuk belajar dan sulit untuk menyenangi matematika pada akhirnya hasil belajar matematika siswa kurang memuaskan (Fatwa dan Djuniadi, 2016: 104). Beberapa permasalahan yang terjadi di kelas yaitu siswa belum terbiasa membangun pengetahuannya sendiri karena masih bergantung kepada penjelasan guru, guru masih terbiasa memberikan rumus dan contoh soal sehingga siswa harus banyak menghafal rumus dan membuat siswa merasa kesulitan. Ada juga siswa yang hafal rumus tetapi tidak bisa menggunakan rumus itu dalam mengerjakan soal apalagi soalnya sudah berbeda dengan contoh soal yang diberikan guru atau soal berbentuk cerita. Oleh karena itu, diperlukan video pembahasan soal terkait materi yang telah atau sedang dipelajari di kelas, sehingga dapat membantu siswa dalam mengingat kembali rumus dan prosedur penggunaannya dalam mengerjakan soal.

Berdasarkan hasil observasi di SMPN 1 Way Tenong menunjukkan bahwa kemandirian belajar siswa masih rendah. Hal ini ditunjukkan masih banyak siswa tidak memiliki inisiatif sendiri dalam belajar, belum bisa mengatur waktu dan strategi belajar sendiri, cenderung mengandalkan teman dalam mengerjakan tugas dan juga jarang siswa yang mengakses internet terkait materi pelajaran mereka. Melihat kondisi kemandirian belajar siswa, maka diperlukan suatu inovasi dalam pembelajaran yang dapat memberikan dampak positif terhadap kemandirian belajar siswa.

Salah satu inovasi model pembelajaran yang dapat digunakan untuk memfasilisasi kegiatan pembelajaran yang menggunakan internet adalah model blended learning. Model blended learning adalah suatu kegiatan pembelajaran yang mengkombinasikan antara pembelajaran tatap muka di kelas dengan kegiatan belajar menggunakan jaringan internet (Rosmiati dkk., 2013: 295). Blended learning adalah integrasi dari pembelajaran tradisional (tatap muka) dengan metode pembelajaran jaringan (Chen dan Liang, 2011: 4153). Pembelajaran tradisional adalah pembelajaran tanpa menggunakan teknologi online, materi pelajaran disampaikan secara tertulis atau lisan (Allen, Seaman, and Garrett, 2007: 5). Pembelajaran online adalah suatu pembelajaran yang menggunakan internet secara online melalui web, 
sehingga proses pembelajaran dilakukan secara tidak langsung atau tanpa tatap muka antara pendidik dan siswa (Himawan, 2011: 139). Ada dua bentuk interaksi dalam model blended learning yaitu asynchronous dan synchronous. Asynchronous adalah bentuk interaksi yang terjadi bersamaan secara real time, sedangkan synchronous adalah bentuk interaksi yang terjadi pada saat tatap muka selama pertemuan di kelas, atau dapat terjadi secara online, melalui chat langsung atau video konferensi (Stein dan Graham, 2014: 19).

Model blended learning tidak dapat sepenuhnya dapat menggantikan interaksi tatap muka guru dengan siswa, tetapi tetap membutuhkan jaminan dan dukungan berkelanjutan dari guru (Poon, 2013: 281). Penelitian yang telah dilakukan menunjukkan bahwa implementasi model pembelajaran blended learning dapat memberikan dampak yang positif terhadap kemandirian belajar (Poon, 2013: 281; Sari, 2013: 42). Model blended learning dapat menambah waktu pembelajaran siswa karena memungkinkan siswa dapat mengulang kembali materi pembelajarannya baik secara mandiri maupun kelompok dan tentunya dapat meningkatkan penguasaan materi yang sedang dipelajarinya (Sandi, 2005: 243). Semakin banyak siswa mengakses informasi pada pembelajaran maka semakin banyak informasi atau materi yang diperoleh. Semakin banyak informasi yang siswa peroleh tentunya akan berdampak positif terhadap penguasaan materi.

Salah satu situs interaktif yang dapat memfasilitasi pembelajaran online dalam model blended learning adalah Edmodo. Edmodo adalah sebuah jejaring sosial pembelajaran berbasis web yang dikembangkan untuk tujuan pendidikan (Manning dan Johnson, 2011: 194). Edmodo diklasifikasikan sebagai jaringan pendidikan sosial karena menyediakan jaringan untuk guru dan siswa-siswanya, guru dan guru lainnya, dan juga di kalangan siswa di seluruh dunia serta tampilan edmodo mirip seperti facebook yang memungkinkan pengguna baru yang menggunakan facebook akan terbiasa menggunakan edmodo (Majid, 2011: 404). Tampilan edmodo mirip seperti facebook, namun memiliki fitur pendidikan yang sesuai dengan pembelajaran pada semua tingkat pendidikan (Zain dkk., 2016: 148). Pengguna dapat mengakses edmodo langsung ke www.edmodo.com atau dapat menginstal menggunakan perangkat smartphone mereka.

Penelitian yang telah dilakukan pada jenjang sekolah menengah atas dan perguruan tinggi menunjukan bahwa model blended learning dapat meningkatkan kemandirian belajar siswa dalam mengikuti pembelajaran (Mayasari, dkk. (2016); Fitriasari dan Sari (2017); Sari (2013). Penelitian ini dilakukan pada jenjang sekolah menengah pertama dan menggunakan situs web edmodo dalam pembelajaran online.

Tujuan penelitian ini adalah untuk mengetahui pengaruh model blended learning terhadap kemandirian belajar matematika siswa.

\section{METODE PENELITIAN}

Jenis penelitian ini adalah eksperimen semu. Desain penelitian dapat dilihat pada Gambar 1. 


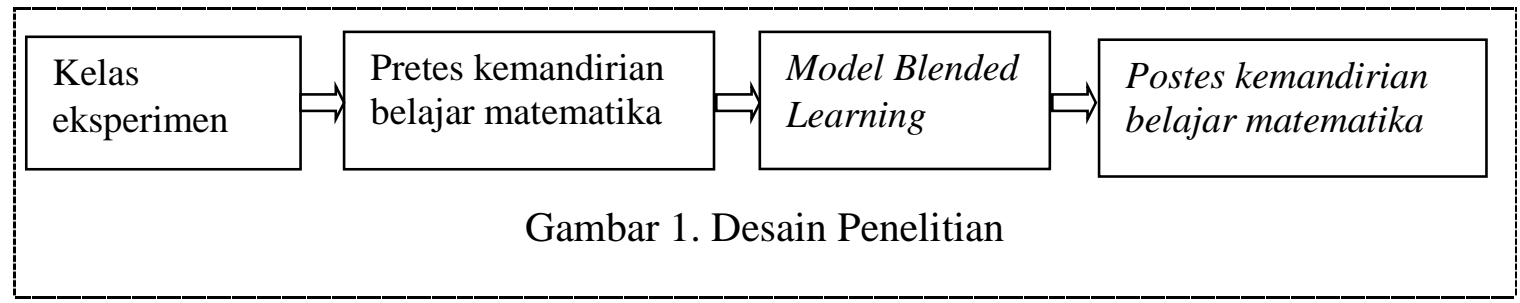

Kelas eksperimen diberi perlakuan dengan model blended learning. Data diperoleh dari hasil pemberian pretes dan postes kemandirian belajar siswa. Pretes digunakan untuk mengetahui tingkat kemandirian belajar awal siswa sebelum perlakuan, sedangkan postes digunakan untuk mengetahui tingkat kemandirian belajar setelah perlakuan. Instrumen yang digunakan dalam penelitian ini adalah instrumen nontes berupa angket kemandirian belajar. Angket kemandirian belajar disusun dengan skala likert dengan kategori selalu, sering, kadang-kadang, jarang, dan tidak pernah. Aspek kemandirian belajar yang diukur adalah inisiatif diri, menetapkan tujuan dan strategi belajar, serta mengevaluasi atau refleksi diri. Populasi dalam penelitian ini adalah seluruh siswa kelas VIII SMP Negeri 1 Way Tenong tahun pelajaran 2017/2018 yang terdiri dari 7 kelas. Kelas yang dipilih adalah kelas VIII E yang terdiri dari 26 siswa. Kelas A, B, C, D masingmasing terdiri dari 30 siswa, sedangkan $\mathrm{F}$ dan $\mathrm{G}$ masing-masing terdiri dari 27 siswa. Kelas eksperimen dipilih secara acak karena sekolah tersebut telah tersedia jaringan internet dan perangkat yang dapat mengakses internet serta siswa telah memiliki kemampuan dalam mengakses internet.

Teknik analisis data menggunakan analisis inferensial. Data pretes dan postes telah hitung dan dinyatakan berdistribusi normal. Untuk mengetahui peningkatan kemandirian belajar matematika digunakan uji gain. Kriteria kemandirian belajar dihitung berdasarkan kriteria menurut Widoyoko (2009) seperti pada Tabel 1.

Tabel 1. Kriteria kemandirian belajar

\begin{tabular}{cc}
\hline Interval & Kriteria \\
\hline$X>84$ & Sangat Tinggi \\
$68<X \leq 84$ & Tinggi \\
$52<X \leq 68$ & Medium \\
$36<X \leq 52$ & Rendah \\
$X \leq 36$ & Sangat Rendah \\
\hline
\end{tabular}

\section{HASIL PENELITIAN DAN \\ PEMBAHASAN}

Penerapan model blended learning dalam pembelajaran matematika terdiri dari pembelajaran tatap muka dan pembelajaran online. Pembelajaran tatap muka dilaksanakan dengan diskusi kelompok mengerjakan lembar kegiatan siswa dan tanya jawab. Pembelajaran online menggunakan bantuan situs web yaitu edmodo yang berisi materi pembelajaran, video pembahasan materi dan soal, diskusi kesulitan belajar dan tugas matematika. Siswa dapat belajar secara mandiri kapanpun dan dimanapun dengan cara mendownload materi ataupun video pembahasan materi dan soal.

Tampilan edmodo yang menyediakan Lembar Kegiatan Siswa dan latihan soal dapat dilihat Gambar 2 dan 3 . 
ISSN 2089-8703 (Print) Vol. 7, No. 3 (2018) 324-333

ISSN 2442-5419 (Online)

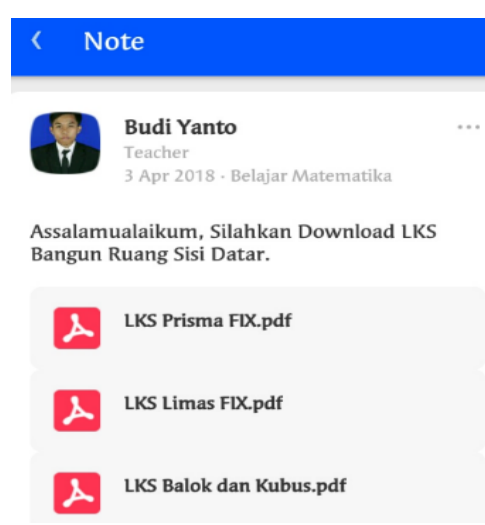

Gambar 2. Tampilan LKS

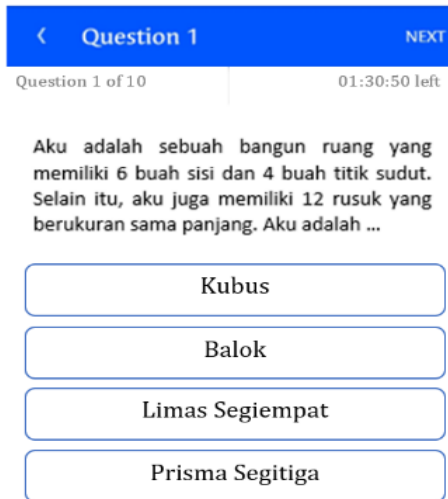

Gambar 3. Tampilan Latihan Soal

Hasil pretes kemandirian belajar dari 26 siswa kelas VIII E SMP Negeri 1 Way Tenong ditunjukan pada Tabel 2.

Tabel 2. Distribusi Pretes Skor Kemandirian Belajar

\begin{tabular}{cccc}
\hline Interval & Kriteria & Frekuensi & $\begin{array}{c}\text { Persentase } \\
(\%)\end{array}$ \\
\hline$X>84$ & Sangat Tinggi & 0 & 0 \\
$68<X \leq 84$ & Tinggi & 1 & 3,85 \\
$52<X \leq 68$ & Medium & 10 & 38,46 \\
$36<X \leq 52$ & Rendah & 15 & 57,69 \\
$X \leq 36$ & Sangat Rendah & 0 & 0 \\
& & 26 & $100 \%$
\end{tabular}

Berdasarkan Tabel 2, dapat matematika di SMP tersebut masih diketahui bahwa kemandirian belajar tergolong rendah. Selanjutnya, hasil matematika siswa sebesar 57,69\% postes kemandirian belajar matematika berada pada kategori rendah. Hal ini ditunjukkan pada Tabel 3. menunjukan bahwa kemandirian belajar

Tabel 3. Distribusi Postes Skor Kemandirian Belajar

\begin{tabular}{cccc}
\hline Interval & Kriteria & Frekuensi & $\begin{array}{c}\text { Persentase } \\
(\boldsymbol{\%})\end{array}$ \\
\hline $\boldsymbol{X}>\mathbf{8 4}$ & Sangat Tinggi & 1 & 3,85 \\
$\mathbf{6 8}<\boldsymbol{X} \leq \mathbf{8 4}$ & Tinggi & 24 & 92,30 \\
$\mathbf{5 2}<\boldsymbol{X} \leq \mathbf{6 8}$ & Medium & 1 & 3,85 \\
$\mathbf{3 6}<\boldsymbol{X} \leq \mathbf{5 2}$ & Rendah & 0 & 0 \\
$\boldsymbol{X} \leq \mathbf{3 6}$ & Sangat Rendah & 0 & 0 \\
& & 26 & $100 \%$ \\
\hline \multicolumn{2}{c}{ Berdasarkan } & Tabel 3, dapat & model blended learning mempengaruhi \\
diketahui bahwa kemandirian belajar & kemandirian belajar. \\
matematika siswa setelah perlakuan & Berdasarkan uji gain untuk \\
sebesar 92,30 \% berada pada kategori & mengetahui peningkatan tingkat \\
tinggi. Hal ini menunjukan bahwa & kemandirian belajar siswa berdasarkan \\
& data pretes dan postest pada kelas
\end{tabular}


eksperimen. Selanjutnya, hasil uji gain Tabel 4.

kemandirian belajar ditunjukkan pada

Tabel 4. Hasil Uji Gain Kemandirian Belajar

\begin{tabular}{cccc}
\hline Interval & Kriteria & Frekuensi & Persentase $(\%)$ \\
\hline$\geq 0.7$ & Tinggi & 1 & 3.85 \\
$0.3-0.7$ & Medium & 23 & 88.46 \\
$<0.3$ & Rendah & 2 & 7.69 \\
\cline { 3 - 4 } & & 26 & $100 \%$
\end{tabular}

Berdasarkan Tabel 4, dapat menunjukkan bahwa semua siswa diketahui bahwa ada 1 siswa $(3,85 \%)$ mengalami peningkatan dalam mengalami peningkatan kemandirian belajar dengan kategori tinggi, 23 siswa $(88,46 \%)$ mengalami peningkatan kemandirian belajar dengan kategori sedang, dan 2 siswa $(7,69 \%)$ mengalami peningkatan kemandirian dengan kategori rendah. Hasil tes gain

kemandirian belajar.

Deskripsi peningkatan kemandirian belajar dapat dilihat pada Tabel 5.

Tabel 5. Hasil Uji Gain Kemandirian Belajar Tiap Aspek

\begin{tabular}{ccc}
\hline Aspect & Nilai Gain & Kriteria \\
\hline Inisitatif diri & 0,6 & Medium \\
Menetapkan tujuan dan & 0,7 & Tinggi \\
strategi belajar & & \\
Evaluasi atau Refleksi diri & 0,5 & Medium \\
\hline
\end{tabular}

Berdasarkan Tabel 5, dapat strategi belajar meningkat dengan diketahui bahwa model blended kriteria tinggi, sedangkan pada aspek learning dapat meningkatkan evaluasi atau refleksi diri meningkat. kemandirian belajar matematika pada tiga aspek yaitu pada aspek inisiatif diri meningkat dengan kriteria medium, pada aspek menetapkan tujuan dan dengan kriteria medium.

Tabel 6. Hasil Uji Hipotesis Antara Pretes dan Postes

\begin{tabular}{|c|c|c|}
\hline & \multicolumn{2}{|c|}{ Test - Value $=68.01$} \\
\hline & & $\begin{array}{c}\text { 95\% Confidence Interval } \\
\text { of the Difference }\end{array}$ \\
\hline & tailed) & Lower $\quad$ Upper \\
\hline $\begin{array}{l}\text { Kemandirian } \\
\text { Belajar }\end{array}$ & 10.774 & 6.37462 \\
\hline $\begin{array}{l}\text { Berdasa } \\
\text { Tabel } 6 \text { antar: } \\
\text { diperoleh nilai } \\
\text { dan signifikan } \\
\text { model blended } \\
\text { terhadap } \\
\text { matematika sis } \\
\text { Berdasa } \\
\text { juga kemandir }\end{array}$ & $\begin{array}{l}\text { an hasil uji-t pada } \\
\text { pre-test dan post-test } \\
\text { hitung sebesar } 10,744 \\
000<\mathrm{p}(0.05) \text {. Maka } \\
\text { learning berpengaruh } \\
\text { mandirian belajar } \\
\text { an uji gain diketahui } \\
\text { n belajar meningkat }\end{array}$ & $\begin{array}{l}\text { setelah melaksanakan pembelajaran } \\
\text { dengan model blended learning. } \\
\text { Penelitian yang telah dilakukan } \\
\text { Mayasari (2016) menunjukan bahwa } \\
\text { model blended learning menggunakan } \\
\text { bantuan Quipper School dapat } \\
\text { mempengaruhi dan meningkatkan } \\
\text { kemandirian belajar siswa X Akutansi } \\
\text { di SMK. Penelitian yang dilakukan } \\
\text { Fitriasari dan Sari (2017) menunjukan }\end{array}$ \\
\hline
\end{tabular}


bahwa model blended learning dapat meningkatkan kemandirian belajar mahasiswa. Selanjutnya penelitian yang dilakukan oleh Sari (2013) menunjukan bahwa model blended learning menggunakan bantuan Quipper School dapat meningkatkan kemandirian belajar mahasiswa.

Seseorang yang memiliki kemandirian belajar dapat mengetahui kapan membutuhkan bantuan dan kapan tidak membutuhkan bantuan orang lain dalam belajar (Ismaniati, Sungkono, dan Wahyuningsih, 2015: 21-22). Guru juga memberikan kesempatan kepada siswa untuk bertanya. Hal ini terlihat ketika proses mengerjakan LKS, siswa akan bertanya kepada guru jika mereka kesulitan mengerjakan LKS. Selain mendapatkan penjelasan oleh guru, siswa yang merasa kesulitan mengerjakan latihan soal ataupun LKS juga akan diarahkan untuk melihat video pembelajaran yang ada di situs web edmodo. Video pembelajaran matematika yang ada pada web edmodo akan memberikan peluang kepada siswa untuk belajar secara mandiri di rumah, kelas, atau tempat lain yang berbeda dengan guru. Pembelajaran online dalam blended learning mendukung pembelajaran mandiri memungkinkan pengulangan pelajaran menyediakan konten pembelajaran digital, membantu pemahaman yang lebih baik dengan visualisasi (Tan, \& Erdoğan, 2004; Yalın, 2000 dalam Cobanoglu \& Yurdaku, 2014: 176). Tsai dkk., (2011) dalam Cobanoglu dan Yurdaku (2014: 192) bahwa keberhasilan pembelajaran telah meningkat melalui praktik blended learning yang mendukung pembelajaran mandiri seperti kegiatan online. Siswa dapat menentukan waktu belajarnya sehingga siswa akan lebih tertarik dengan belajar matematika. Pembelajaran model blended learning dapat meningkatkan akses informasi, kenyamanan, pengalaman belajar, dan fleksibilas belajar karena siswa dan guru dapat berpartisipasi dalam kelas secara online (Stein dan Graham, 2014: 14).

Penggunaan teknologi dalam blended learning dapat meningkatkan inisiatif siswa untuk belajar apalagi ditambah dengan video pembelajaran yang benar-benar terkait dengan pembelajaran yang sedang mereka pelajari. Siswa yang mengakses materi pelajaran terlebih dahulu, tentunya membuat mereka mengetahui apa yang akan dipelajari dan juga mereka akan lebih siap untuk belajar (Dwiharja, 2015: 340). Oleh karena itu, materi pembelajaran dan video pembelajaran telah di upload sebelumnya di situs web edmodo. Pembelajaran di kelas dalam model blended learning juga diadakan kegiatan diskusi dan presentasi kelompok. Kegiatan diskusi dan presentasi kelompok, dapat melatih siswa berkomunikasi dan meningkatkan kepercayaan diri mereka yang pada akhirnya siswa memiliki semangat dalam belajar (Marini, dkk. 2017: 475). Situs web edmodo yang digunakan dapat membantu siswa dalam belajar secara mandiri dimanapun dan kapanpun menggunakan perangkat komputer atau smartphone mereka dengan mengakses LKS, latihan soal, menonton video pembahasan soal dan materi serta dapat berdiskusi dengan guru atau siswa lainnya. Siswa juga diberikan pertanyaan terkait kesulitan belajar matematika. Siswa yang masih kesulitan memahami materi akan dijelaskan kembali di pembelajaran tatap muka. Model blended learning dapat mengurangi jarak yang selama ini ada diantara siswa dan guru dan dapat meningkatkan interaksi diantara kedua belah pihak (Jusoff and Khodabandelou, 2009: 82). Interaksi dapat dilakukan secara langsung (synhcronous), dan 
tidak secara langsung (asynchronous). Siswa yang malu bertanya pada saat pembelajaran tatap muka, dapat memberikan pertanyaan kepada guru melalui fitur chat pada web edmodo. Kemandirian belajar siswa dapat disebabkan oleh aktivitas online pada pembelajaran blended learning (Cobanoglu dan Yurdaku, 2014: 191).

Implikasi yang terjadi ketika model blended learning diterapkan dalam pembelajaran matematika adalah dapat mempengaruhi kemandirian belajar matematika siswa. Model blended learning cocok digunakan dalam pembelajaran matematika siswa dan tentunya dapat meningkatkan kemandirian belajar matematika siswa. Model blended learning memungkinkan siswa dapat belajar secara mandiri menggunakan fasilitas online model tersebut. Pembelajaran online tidak dapat menggantikan pembelajaran di kelas. Pembelajaran online dapat dijadikan suplemen tambahan dalam pembelajaran di kelas. Keterbatasan waktu dalam pembelajaran di kelas dapat di tutupi melalui pembelajaran online.

\section{KESIMPULAN DAN SARAN}

Berdasarkan hasil penelitian, dapat disimpulkan bahwa pembelajaran dengan model blended learning dapat mempengaruhi kemandirian belajar matematika siswa. Kemandirian belajar dapat difasilitasi oleh guru dengan menyediakan sumber belajar yang dapat diakses oleh siswa. Perlunya video pembahasan materi dan soal dapat membantu siswa belajar secara mandiri mengenai konsep dan prosedur penggunaan rumus yang tepat terkait materi matematika yang sedang mereka pelajari.

\section{DAFTAR PUSTAKA}

Allen, I. E., Seamen, J., \& Garret, R. (2007). Blending in: The Extent and Promise Of Blended Education in The United States. Needam: The Sloan Consortium. Amiluddin, R \& Sugiman. (2016). Pengaruh problem posing dan PBL terhadap prestasi belajar, dan motivasi belajar mahasiswa pendidikan matematika Jurnal Riset Pendidikan Matematika, Vol. 3 N. 1, Hal. $100-108$.

Aziz, A., \& Basry. (2017). Hubungan Antara Kompetensi Guru dan Kepercayaan Diri Dengan Kemandirian Siswa SMPN 2 Pangkalan Susu. Jurnal Psychomutiara, 1(1), 15-29.

Beishuizen J., Steffens K. (2011). A Conceptual Framework for Research on Self-Regulated Learning. Technology Enhanced Learning Environments. Technology enhanced learning, Vol. 5, Sense Publishers.

Chen, C, \& Liang. T. (2011). The Design and Implementation of a Blended Knowledge Management Course in Higher Education. Procedia Engineering. Vol. 2011. No. 15, Hal. 4152-4156.

Cobanoglu, A., \& Yurdakul, B. (2014). The Effect of Blended Learning On Students' Achievement, Perceived Cognitive Flexibility Levels And Self-Regulated Learning Skills. Journal of Education and Practice. Vol. 5, No. 22, Hal. 176-197.

Dwiharja, L. M. (2015). Memanfaatkan Edmodo Sebagai Media Pembelajaran Akuntansi. Prosiding Seminar Nasional 9 Mei 2015 Universitas Negeri Yogyakarta. 
Eliserio, D. (2012). Self-regulated learning and mathematics achievement in a fourth-grade classroom self-regulated learning and mathematics achievement in a fourth grade. Master of Education Program Theses.

Fatwa, A., \& Djuniadi. (2016). Strategi Blended learning untuk Meningkatkan Hasil Belajar Pokok Bahasan Persamaan dan Fungsi Kuadrat Mata Pelajaran Matematika. Electronic Journal Politeknik Harapan Bersama Tegal. Vol. 1, No. 1, Hal. 103108.

Fitriasari, P., \& Sari, N. (2017). Implementasi Blended Learning untuk Meningkatkan Kemandirian Belajar Mahasiswa pada Mata Kuliah Metode Numerik. Seminar Nasional Matematika dan Aplikasinya, Surabaya, Universitas Airlangga, 160-166.

Himawan, H. (2011). Analisa dan Perancangan Sistem Pembelajaran Online Menggunakan Metode Parsing. Telematika. Vol. 7, No. 2, Hal. 139-148.

Ismaniati, Ch., Sungkono, \& Wahyuningsih, D. (2015). Model Blended Learning Untuk Meningkatkan Kemandirian Belajar dan Daya Tarik Dalam Perkuliahan. Jurnal Penelitian Ilmu Pendidikan. Vol. 8, No. 2, Hal. 19-27.

Jusoff, K. \& Khodabandelou, R. (2009). Preliminary Study on the Role of Social Presence in Blended learning Environment in Higher Education. International Education Studies. Vol. 2, No. 4, Hal. 79-83.
Lestari \& Yudhanegara. (2015). Penelitian pendidikan matematika: panduan praktis menyusun skripsi, tesis, dan laporan penelitian dengan pendekatan kuantitatif, kualitatif dan kombinasi disertai dengan model pembelajaran dan kemampuan matematis. Bandung: PT Refika Aditama.

Majid, N. A. (2011). The Use of Information Technology in Teaching English: An Attempt To Develop Student-Centered Learning At Telkom Polytechnic. Prosiding Konferensi Nasional ICT-M Politeknik Telkom (KNIP).

Manning, S., \& Johnson, K. E. (2011). The Technology Toolbelt for Teaching. San Fracisco: JosseyBass.

Marini, A., Rahman, C., \& Chandra, T. D. (2017). Peningkatan motivasi belajar siswa melalui penerapan pendekatan realistic mathematics education (RME). Jurnal Pendidikan: Teori, Penelitian, dan Pengembangan, 2(4), 470477.

Mayasari, F., Santoso, S., \& Octoria, D. (2016). Upaya Meningkatkan Kemandirian Belajar Siswa Melalui Penerapan Blended Learning Berbantuan Quipper School. Jurnal Tata Arta UNS. Vol. 2, No. 3, Hal. 148-161.

Poon, J. (2013). Blended Learning: An Institutional Approach for Enhancing Students' Learning Experiences. MERLOT Journal of Online Learning and Teaching. Vol. 9, No. 2, Hal. 271-289.

Purnamasari, Y. (2012). Pengaruh Model Pembelajaran Kooperatif Tipe Teams Games Tournament (TGT) Terhadap Kemandirian 
Belajar dan Peningkatan Kemampuan Penalaran dan Koneksi Matematik Peserta Didik SMPN 1 Kota Tasikmalaya. Jurnal Pendidikan dan Keguruan. Vol. 1, No.1, Hal. 1-11.

Rosmiati., Jatmiko, B., \& Madlazim. (2013). Pengembangan Perangkat Pembelajaran Blended Learning Model Cooperative untuk Meningkatkan Hasil Belajar Fisika SMA Kelas XI. Pendidikan Sains Pascasarjana Universitas Negeri Surabaya. Vol. 3, No. 1, Hal. 294-298.

Rosmiati., Jatmiko, B., \& Madlazim. (2013). Pengembangan perangkat pembelajaran blended learning model cooperative untuk meningkatkan hasil belajar fisika SMA kelas XI. Pendidikan Sains Pascasarjana Universitas Negeri Surabaya, Vol. 3, No. 1), Hal. 294-298.

Sandi, G. (2006). Pengaruh Blended Learning Terhadap Hasil Belajar Kimia ditinjau dari Kemandirian Siswa. Jurnal Pendidikan dan Pengajaran. Vol. 45, No. 3, Hal. 241-251.

Sari, A. R. (2013). Strategi blended Learning untuk Peningkatan Kemandirian Belajar dan Kemampuan Critical Thinking Mahasiswa di Era Digital. Jurnal Pendidikan Akuntansi Indonesia. Vol. 1, No. 2, Hal. 32-43.

Stein, J., \& Graham, C. R. (2014). Essentials for Blended Learning: A Standards-Based Guide. New York: Routledge.

Sujoko. (2013). Pemanfaatan Teknologi Informasi dan Komunikasi sebagai Media Pembelajaran di
SMP Negeri 1 Geger Madiun. Jurnal Kebijakan dan Pengembangan Pendidikan. Vol. 1. No. 1, Hal. 71-77.

Widoyoko, P. E. (2009). Evaluasi Program Pembelajaran:

Panduan Praktis Bagi Pendidik dan Calon Pendidik. Yogyakarta: Pustaka Pelajar.

Zain, F. M., Sahimi, S. M., Hanafi, E., Halim, A. H. A., \& Alias, A. K. (2016). A Study of Students' Interaction in Edmodo Social Learning Platform. Envisioning the Future of Online Learning Selected Papers from The International Conference on ELearning 2015. Singapura: Springer Science Business Media. 